\title{
Enlargement Of Surgical Incision
}

National Cancer Institute

\section{Source}

National Cancer Institute. Enlargement Of Surgical Incision. NCI Thesaurus. Code C50835.

A surgical procedure to extend the length of an initial surgical incision. 